\title{
Erratum to: Effects of heat stress on the gene expression of nutrient transporters in the jejunum of broiler chickens (Gallus gallus domesticus)
}

\author{
Xiaolei Sun ${ }^{1}$ - Haichao Zhang ${ }^{1}$ - Ardashir Sheikhahmadi ${ }^{2}$ Yufeng Wang ${ }^{3}$. \\ Hongchao Jiao $^{1} \cdot$ Hai Lin ${ }^{1} \cdot$ Zhigang Song ${ }^{1}$
}

Published online: 9 May 2015

(C) ISB 2015

\section{Erratum to: Int J Biometeorol}

DOI 10.1007/s00484-014-0829-1

In Table 2, the units for the plasma level of uric acid should be $\mu \mathrm{Mol} / \mathrm{L}$, not $\mathrm{mMol} / \mathrm{L}$.

The Editorial Board would like to thank Fariborz Khajali of Shahrekord University (Islamic Republic of Iran) for bringing this error to our attention.

The online version of the original article can be found at http://dx.doi.org/ 10.1007/s00484-014-829-1.

\section{Zhigang Song}

zhigangs@sdau.edu.cn

1 Department of Animal Science and Technology, Shandong Agricultural University, Taian 271018, Shandong, China

2 Department of Animal Science, Faculty of Agriculture, University of Kurdistan, Sanandaj 6617715175, Iran

3 Laboratory of Livestock Physiology, Department of Biosystems, KU Leuven, Kasteelpark Arenberg 30, 3001 Leuven, Belgium 